\title{
Perinatal Nicotine Attenuates the Hypoxia-Induced Up-regulation of Tyrosine Hydroxylase and Galanin mRNA in Locus Ceruleus of the Newborn Mouse
}

\author{
H. RONNY WICKSTRÖM, CHRISTOPHE MAS, MICHEL SIMONNEAU, HANS HOLGERT, \\ TOMAS HÖKFELT, AND HUGO LAGERCRANTZ \\ Department of Woman and Child Health (H.R.W., H.H., H.L.), Department of Neuroscience (H.R.W., \\ T.H.), Karolinska Institutet, 17177 Stockholm, and Laboratoire de Neurologie et Physiologie du \\ Developpement (C.M., M.S.), INSERM E9935, Hôpital Robert Debré, Paris, France
}

\begin{abstract}
The effect of perinatal nicotine exposure on the hypoxic response in the newborn mouse was examined, with special reference to the catecholaminergic system. We studied transcripts for the catecholamine synthesizing enzyme tyrosine hydroxylase (TH) and the neuropeptide galanin (GAL) in locus ceruleus (LC) and adrenal medulla at different times after birth and postnatal hypoxia. We thereafter investigated how perinatal nicotine affected these mRNA levels, as well as the ability of the newborn to survive severe hypoxia. TH mRNA levels increased postnatally in both LC and adrenals, reaching peak values at $24 \mathrm{~h}$ postnatally and thereafter stabilizing at lower levels. GAL mRNA also increased in the LC but did not decrease after $24 \mathrm{~h}$. Acute hypoxia $\left(5 \% \mathrm{O}_{2}\right.$ for $\left.60 \mathrm{~min}\right)$ elicited increases in $\mathrm{TH}$ and GAL mRNA levels in the LC after $24 \mathrm{~h}$. However, TH mRNA levels in the adrenals did not change. Perinatal nicotine exposure increased mortality after hypoxia (from $0 \%$ to $16.9 \%$ ). Moreover, hypoxia-induced increases in TH and GAL mRNA levels in the
\end{abstract}

\section{ABSTRACT}

LC were not observed in nicotine-treated pups. Nicotine also decreased basal TH mRNA levels in the adrenals. The present results suggest (1) that the postnatal increases in adrenal $\mathrm{TH}$ mRNA levels are not directly due to hypoxia at birth, and (2) that the increased mortality seen after hypoxia in nicotine pups concurs with a perturbed LC function in these animals. A deficient catecholamine synthesis in the adrenals may also contribute to the detrimental effect of prenatal exposure to nicotine on the response to hypoxia. (Pediatr Res 52: 763-769, 2002)
Abb
E18, embryological day 18
GAL, galanin
LC, locus ceruleus
NA, noradrenaline
TH, tyrosine hydroxylase

Smoking during pregnancy is known to produce intrauterine growth retardation, spontaneous abortion, increased incidence of perinatal brain damage and an increased risk of sudden infant death syndrome (SIDS) in the newborn (1). Although tobacco smoke contains a wide variety of potentially fetotoxic substances, animal studies have pointed to nicotine itself as a neuroteratogen and producing abnormal CNS development (2, 3). Also, studies in newborn rat have shown that nicotine administration leads to a decreased survival (4) and an impaired autoresuscitation (5) when exposed to severe hypoxia.

\footnotetext{
August 21, 2001; March 18, 2002.
}

Correspondence: Ronny Wickström, MD, Neonatal Unit, Q2:07, ALB, Karolinska Sjukhuset, 17176 Stockholm, Sweden; e-mail: ronny.wickstrom@kbh.ki.se

This study was supported by grants from the Swedish MRC (04X-2887), Swedish Match, Stiftelsen Frimurarna Barnhuset, Sällskapet Barnavård, Stiftelsen Elsa Goljes Minne, Marianne and Marcus Wallenbergs Foundation, INSERM, Naitre \& Vivre Foundation and an Unrestricted Bristol-Myers Squibb Neuroscience Grant.

DOI: 10.1203/01.PDR.0000032154.09425.3C
The release of catecholamines from the adrenals and the brainstem has been implicated as being altered in these animals (4). In this study, we therefore investigated the effect of prenatal exposure to nicotine on tyrosine hydroxylase $(\mathrm{TH})$ mRNA levels in the locus ceruleus (LC) and adrenal gland after hypoxia. In addition we monitored mRNA levels for galanin (GAL) (6), a peptide that is co-expressed with $\mathrm{TH}$ in many LC neurons $(7,8)$. The study was performed in the mouse, to extend information to this species for future respiratory studies in transgenic mice.

Immediately following birth, basal levels of circulating catecholamines are high as the transition from intra- to extrauterine life is associated with a massive surge of these compounds (9), mainly originating from the adrenals (10). These catecholamines have several essential functions in the newborn, e.g. stimulation of lung liquid absorption, sustaining metabolic and cardiac homeostasis (11) and protection of the 
neonate during hypoxia $(12,13)$. There is also, apart from the increased levels of circulating catecholamines, an increase in the noradrenergic turnover in the brain immediately after birth (14), which is probably involved in the general arousal during the first hours of postnatal life. An increased activity in the LC neurons at birth, with a concomitant release of noradrenaline, could potentially result in increased levels of TH mRNA in these neurons, as is the case in the adrenals of the rat (15). As a basis for the study of hypoxia and nicotine we therefore examined the basal expression of TH and GAL mRNA in the newborn mouse at different times after birth.

Exposing the newborn rat to hypoxia increases NA turnover in the brainstem $(16,17)$, as well as inducing catecholamine secretion from the adrenals (4). In the neonate, this adrenal catecholamine secretion appears to lack coupling to increased synthesis of TH mRNA, thus contrasting from the adult (18). Whether or not acute hypoxia leads to increased levels of TH mRNA in the LC has not previously been studied. Furthermore, GAL may influence the activity of the noradrenergic LC neurons, and thus the secretion of NA in the CNS. GAL inhibits NA release in cortex (19), and exerts direct effects on the LC neurons (20). GAL has also been shown to increase after birth in several nuclei of the brainstem of the rat involved in respiratory control (21) and may play a role in the response to acute stress such as birth or postnatal hypoxia.

Thus the aim of this study was to, in the mouse, examine the response of the LC and adrenals, as measured by mRNA levels of TH and GAL, to hypoxia and whether this response was altered in animals prenatally exposed to nicotine.

\section{MATERIALS AND METHODS}

Animals. NMRI mice pups of both sexes (B\&K Universal, Sollentuna, Sweden) were studied on embryological day 18 (E18, d 19 being normal day of birth) and at different postnatal ages; $3 \mathrm{~h}, 6 \mathrm{~h}, 12 \mathrm{~h}, 24 \mathrm{~h}, 48 \mathrm{~h}$ and $92 \mathrm{~h}$. The number of animals studied in each group was $n=6$, being from two (E18 group) or three different litters. After decapitating the dam, pups in the E18-group were delivered by caesarean section and immediately killed by decapitation and placed on ice. Postnatal groups were born naturally and left with their mothers until killed at assigned times. Animals were kept on a regular $12 \mathrm{~h}$ light: $12 \mathrm{~h}$ dark cycle and treated according to the guidelines approved by the local ethics committee (see below). For the study of the effects of postnatal hypoxia, pups were born naturally and left with their mothers for $24 \mathrm{~h}$. At this time, they were divided into two groups; one control group breathing normoxic room air for $60 \mathrm{~min}$ and one group being subjected to a hypoxic gas mixture (5\% $\mathrm{O}_{2}$ and $4 \% \mathrm{CO}_{2}$ in $\mathrm{N}_{2}, \mathrm{n}=6$, from three different litters). The addition of $4 \% \mathrm{CO}_{2}$ serves to avoid hypocapnia as ventilation is increased due to the decreased oxygen levels (22). The volume of the box in which exposure was performed was 200 $\mathrm{mL}$ and the flow rate of air or hypoxic mixture $1.5 \mathrm{~L}$ per min, thus rapidly flushing the box without further retention of carbon dioxide. Levels of $\mathrm{O}_{2}$ and $\mathrm{CO}_{2}$ were continuously monitored using a gas analyser (Arelco, Fontenay-sous-bois, France). The pressure in the box was also monitored to avoid hyperbaric pressure. The temperature of the box was main- tained at $34^{\circ} \mathrm{C}$ using a SH1D Hotplate (Stuart Scientific, Redhill, UK). After exposure to air/hypoxic mixture the box was flushed with air $\left(20.3 \% \mathrm{O}_{2}\right.$ and $\left.0.1 \% \mathrm{CO}_{2}\right)$, and pups were left for $15 \mathrm{~min}$ before survival was assessed. Pups were considered dead when there was no response to painful stimulation and no heart activity upon opening the thorax. Surviving pups were returned to their mothers and left for different times $(6 \mathrm{~h}, 12 \mathrm{~h}$, and $24 \mathrm{~h})$ before they were killed by decapitation. Brains and right adrenals of all pups were rapidly dissected out, mounted and frozen on dry ice for in situ hybridization. In the study of hypoxic mortality following prenatal nicotine exposure, the number of animals studied was $n=44$ (nicotine) from four different litters and $n=59$ (control) from six different litters. Six animals from each group ( $n=6$, being from three different litters) were thereafter randomly selected for in situ hybridization.

Administration of nicotine. Osmotic minipumps (Model 2002, Alzet, Palo Alto, CA, U.S.A.) were used to administer nicotine to fetuses. Insertion of the pump was made on the 5th day of gestation after lightly anesthetizing the dam with ether. The osmotic pump was placed s.c. on the back, the incision was closed with a metal clip, and the animals were returned to their cages for recovery. The pumps contained either nicotine bitartrate (Sigma Chemical Co. Chemical Co., St. Louis, MO, U.S.A.) dissolved in sodium chloride $(n=6)$ or only sodium chloride for the control group $(n=6)$. The concentration of nicotine was designed to deliver $6 \mathrm{mg}$ solution/ $\mathrm{kg}$ body weight $\times$ day, calculated for the initial weight. These pumps deliver their content for at least $14 \mathrm{~d}$, thus lasting the entire remaining gestational period and do not cause any signs of maternal hypoxia/ischemia, as do injections of nicotine. The dose regimen of nicotine used here produces plasma levels in rat resembling those seen in heavy smokers in man $(2,23)$.

In situ hybridization. The frozen tissue was cut into $14 \mu \mathrm{m}$ thick sections in a cryostat (Microm, Heidelberg, Germany) and thawed onto ProbeOn microscope slides (Fisher Scientific, Pittsburgh, PA, U.S.A.). Synthetic oligonucleotides complementary to nucleotides $152-199$ of rat prepro(pp)GAL (24) and 1-48 of rat TH (25) (Scandinavian Gene Design, Köping, Sweden) were used as probes. The probes were labeled at the $3^{\prime}$ end with $[\alpha-[35 S]$ thio]dATP (Du Pont New England Nuclear, NEN, Boston, MA, U.S.A.) using terminal deoxynucleotidyltransferase (Amersham Corp., Amersham, UK) and purified through QIAquick nucleotide removal columns (QIAGEN, Hilden, Germany).

Hybridization was performed on the nonfixed tissue samples at $42^{\circ} \mathrm{C}$ for $18 \mathrm{~h}$, as described previously (26). In brief, sections were hybridized in a solution containing $50 \%$ formamide, $4 \times$ standard sodium citrate $(0.15 \mathrm{M} \mathrm{NaCl}$ and $0.015 \mathrm{M}$ sodium citrate), $1 \times$ Denhardt's solution $(0.02 \%$ each of BSA, Ficoll and polyvinylpyrrolidone), $0.02 \mathrm{M}$ sodium phosphate ( $\mathrm{pH} 7.0$ ), $500 \mathrm{mg} / \mathrm{mL}$ salmon testis DNA and $200 \mathrm{mM}$ DTT. After hybridization the sections were rinsed in $\mathrm{SSC}$ at $55^{\circ} \mathrm{C}$ for 60 min with four changes of the rinsing medium and then cooled to room temperature in SSC. Sections were then briefly rinsed in distilled water, dehydrated in $60 \%$ and $95 \%$ ethanol and allowed to air-dry. As a control, an excess (100x) of unlabeled probe was added to the incubation cocktail. Slides with adrenal 
sections were covered with Hyperfilm- $\beta$ max autoradiography film and exposed at $-20^{\circ} \mathrm{C}$ for $3 \mathrm{~d}$. Sections were thereafter dipped in NTB2 liquid photo emulsion (Kodak, Rochester, NY, U.S.A.) diluted 1:1 with distilled water and exposed at $-20^{\circ} \mathrm{C}$ for 3 weeks. After exposure, slides were developed with D19 (Kodak), fixed and analyzed in a Nikon Microphot FX-microscope (Nikon, Tokyo, Japan). Photographs of the unstained sections (T-max, ASA 100, Kodak) were taken under darkfield conditions and, after staining with toluidine blue, under bright field conditions.

Quantification. Computerized quantification of emulsiondipped slides was performed with a Nikon Microphot FXmicroscope and Macintosh computer using the public domain NIH Image program (developed at the U.S. National Institutes of Health and available on the Internet at http://rsb.info.nih.gov/nih-image/). The borders of measurement were chosen by observation and, after staining, controlled under bright field conditions. Repeated measurements were performed to obtain a mean intensity of the area, which was corrected for the background tissue intensity. All comparisons between groups were made on sections hybridized together, under identical conditions and exposed for the same time period to the liquid emulsion.

Statistical considerations. Statistical analysis of mRNA expression was performed using analysis of variance (ANOVA) followed by the Bonferroni multiple comparisons test and Bartlett test for homogeneity of variances. A confidence level of $p<0.05$ was considered significant. The number of animals in each group was $n=6$, being from two (for prenatal pups) or three different litters. In the study of mortality after hypoxia following prenatal nicotine exposure versus control there were between 44 and 59 animals in each group from at least four different litters. Six animals from each group were thereafter randomly selected for in situ hybridization and processed as above.

Ethical considerations. These experiments have been approved by the local ethical committee, i.e. Stockholms norra djurförsöksetiska nämnd (Dnr N297/95 and N321/98).

\section{RESULTS}

Postnatal expression of TH and GAL mRNA. Following vaginal delivery, levels of TH mRNA increased significantly in the $\mathrm{LC}$ at $24 \mathrm{~h}(p<0.01)$, when it also reached its maximum value. In the adrenals, TH mRNA levels increased at $6 \mathrm{~h}(p<$ 0.05 ) and then increased further to reach a maximum value of more than a 6 -fold increase at $24 \mathrm{~h}(p<0.001$ compared with younger animals). Thereafter levels decreased in both tissues at 48 (not significant) and $92 \mathrm{~h}(p<0.01$ in the adrenal only). GAL mRNA in the LC increased significantly at $24 \mathrm{~h}(p<$ 0.05 compared with E18 and $3 \mathrm{~h}$ pups), remained at the same level at $48 \mathrm{~h}$ before tending to increase further at $92 \mathrm{~h}$ (not significant compared with 24 and 48 h, Fig. 1, 2, and 3).

Effects of acute hypoxia on TH and GAL mRNA. Based on the $\mathrm{LC}$ values we chose $24 \mathrm{~h}$ to be a suitable age to study the response to hypoxia, as levels of TH and GAL then seemed to have reached a plateau. For this purpose, pups in the hypoxic group were subjected to $60 \mathrm{~min}$ of a hypoxic gas mixture $(5 \%$
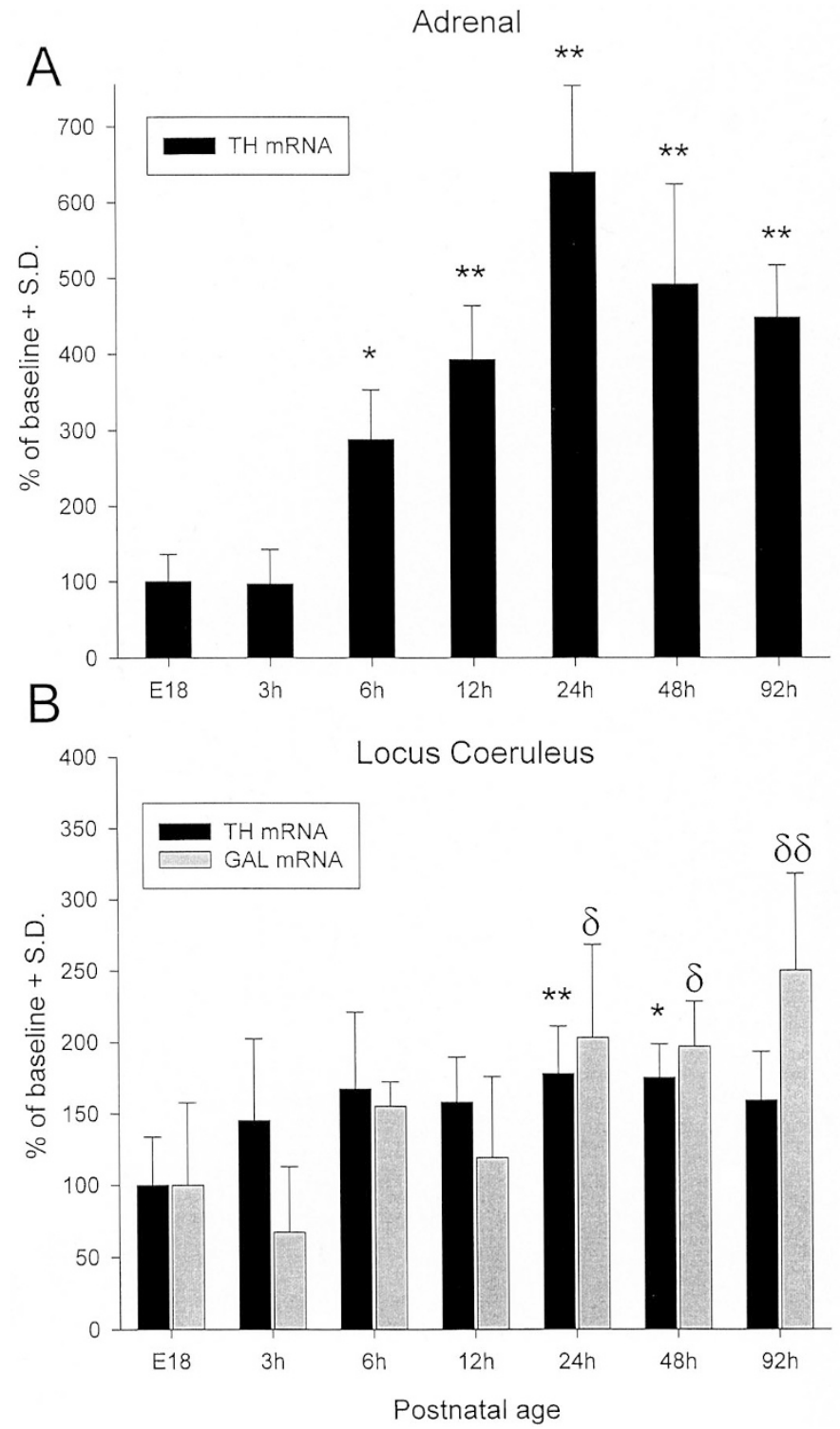

Figure 1. Expression of TH (black bars) and GAL (gray bars) mRNA at different times before and after birth in the adrenals $(A)$ and locus ceruleus $(B)$. All values are expressed as percentage of E18 group; also note the different scales in graphs. Levels of TH mRNA in the LC increased significantly at $24 \mathrm{~h}$ and thereafter decreased. Expression of GAL mRNA in the LC increased significantly after $24 \mathrm{~h}$ and thereafter tended to increase further at $92 \mathrm{~h}$. In the adrenals, TH mRNA levels increased significantly at $6 \mathrm{~h}$ and reached a maximum value at $24 \mathrm{~h}$ postnatally. Thereafter expression decreased at 48 and 92 h. *(for TH) and $\delta$ (for GAL) $p<0.05, * * / \delta \delta p<0.01$, compared with levels at E18.

$\mathrm{O}_{2}$ and $4 \% \mathrm{CO}_{2}$ in $\mathrm{N}_{2}$ ). Expression of $\mathrm{TH}$ and GAL mRNA was then studied at $6 \mathrm{~h}, 12 \mathrm{~h}$, and $24 \mathrm{~h}$ after hypoxia. TH mRNA increased more in the LC after hypoxia at $24 \mathrm{~h}$ compared with normoxic groups. GAL mRNA tended to increase at 6 and $12 \mathrm{~h}$, but the increase was first significant at $24 \mathrm{~h}$. Also, there were tendencies toward increased levels in the control groups at 12 and $24 \mathrm{~h}$, but significance was not reached. $\mathrm{TH}$ mRNA in the adrenals, however, did not increase significantly after hypoxia at any time studied, although there was a tendency toward an increase at $6 \mathrm{~h}$ and, to a lesser degree, at $12 \mathrm{~h}$ (Fig. 4 and 5). 

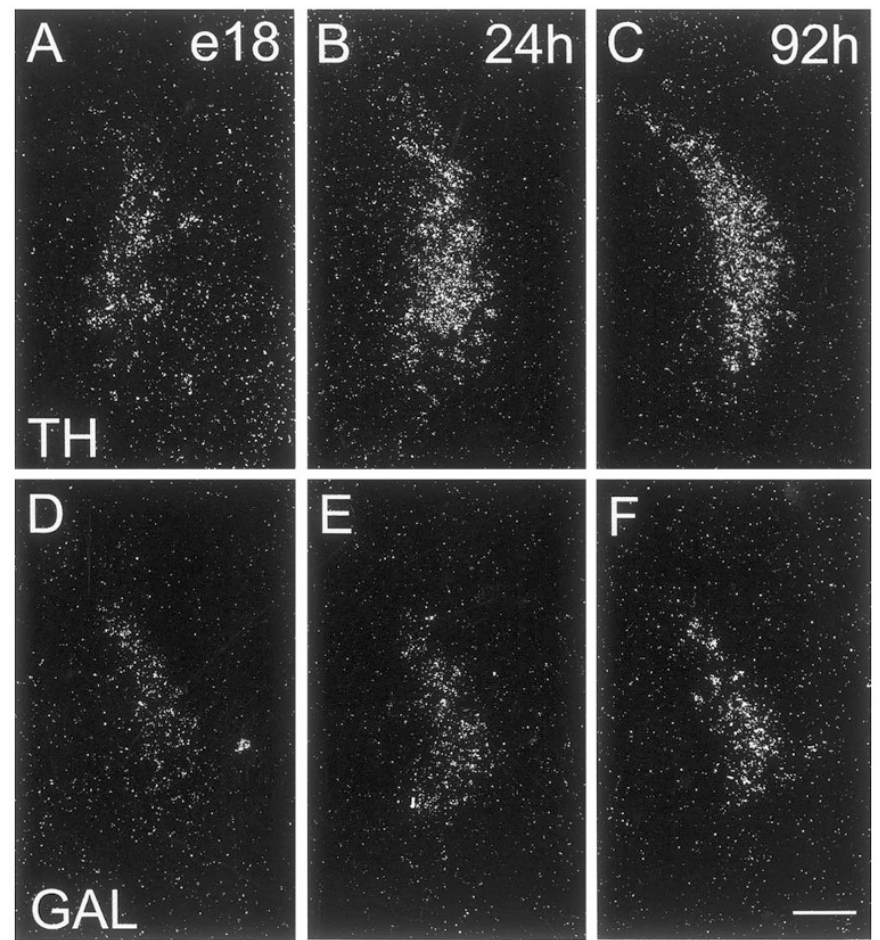

Figure 2. Darkfield images of the TH and GAL mRNA expression in the LC on E18 $(A$ and $D), 24 \mathrm{~h}(B$ and $E)$ and $92 \mathrm{~h}$ after birth $(C$ and $F)$. Both TH and GAL were up-regulated postnatally. TH mRNA levels reached a maximum value at $24 \mathrm{~h}$ and thereafter gradually decreased, whereas GAL mRNA levels increased further at $92 \mathrm{~h}$. Images are transverse sections of the brainstem with the ventral surface facing downwards. Bar indicates; $200 \mu \mathrm{m}$.

Effects of prenatal nicotine. The effect of prenatal exposure to nicotine was studied only $24 \mathrm{~h}$ after hypoxia. Nicotine infusions using osmotic pumps placed s.c. on the back did not cause any signs of hypoxia or ischemia, such as cyanosis or blanching of the skin, commonly seen after nicotine injections. Nor was the size of the litters or the weight of the pups, measured on postnatal day 1 , significantly altered following nicotine (data not shown). Pups prenatally exposed to nicotine showed an increased mortality following the hypoxic period (10/59 or $16.9 \%$, compared with $0 \%$ in control animals, $p<$ $0.05)$. Animals in the nicotine group that died during hypoxia were excluded from the study of mRNA levels. In the control group TH and GAL mRNA were both up-regulated in the LC $24 \mathrm{~h}$ after hypoxia (Fig. 6), thus resembling the response in the previous set of experiments (see above). This up-regulation was not seen in animals exposed to nicotine, although a slight, not significant increase of expression of TH and GAL mRNA was observed. As demonstrated above, hypoxia did not affect TH mRNA levels in the adrenals of control pups. However, there was a significant decrease in the basal levels of $\mathrm{TH}$ mRNA in the adrenals of those pups that had received prenatal nicotine (Fig. 3 and 6). Exposure to hypoxia did not significantly alter these low levels, being coherent with previous results. In control experiments, after incubation with an excess of respective cold probe, neither the TH nor GAL mRNA signals described above could be detected.
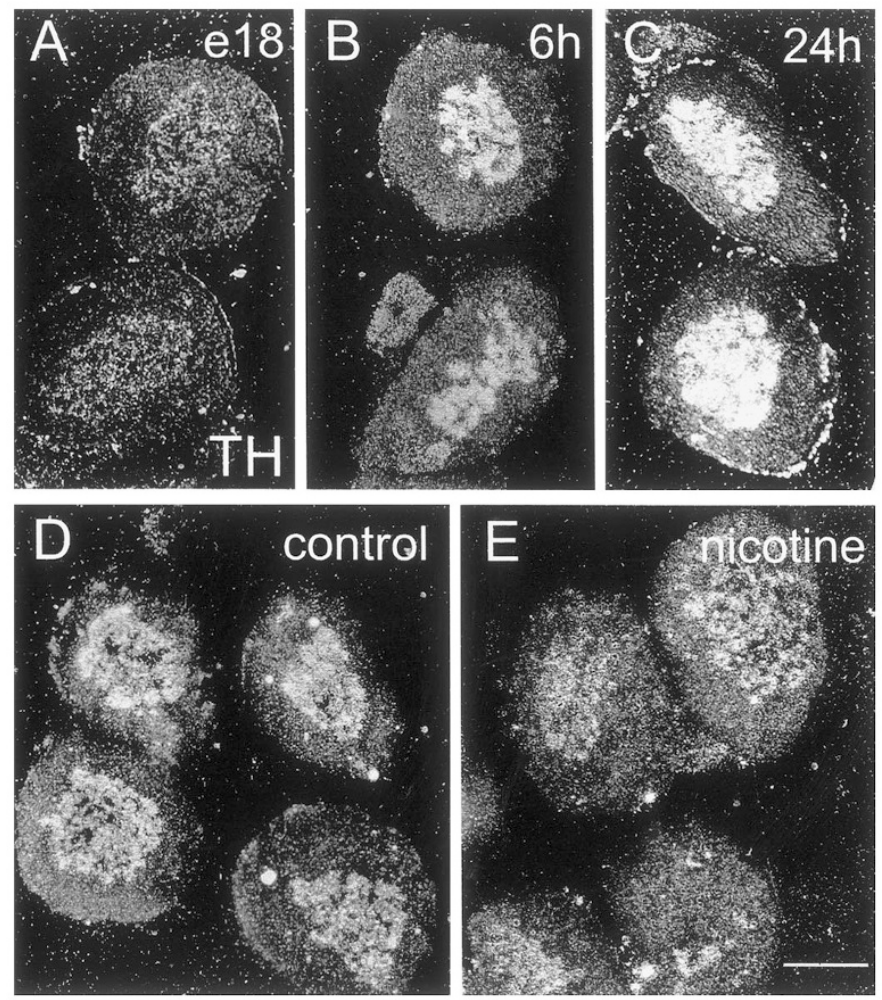

Figure 3. Darkfield images of TH mRNA expression in the adrenals. Basal levels increased postnatally reaching maximum levels at $24 \mathrm{~h}$ of age $(A-C)$. Postnatal hypoxia did not elicit increased TH mRNA expression (not shown). Prenatal exposure to nicotine decreased basal levels of TH mRNA postnatally, measured at $48 \mathrm{~h}$ of age $(D-E)$. Bar indicates $500 \mu \mathrm{m}$.

\section{DISCUSSION}

This study demonstrates that levels of TH mRNA in the LC and adrenal medulla and of GAL mRNA in the LC of the mouse are all up-regulated following birth, which is in agreement with studies on rat. Acute hypoxic challenge also increases levels of TH and GAL mRNA in the LC after $24 \mathrm{~h}$, suggesting that these neurons are involved in the response to hypoxic stress. On the other hand, hypoxic challenge does not affect levels of TH mRNA in the adrenals, corroborating earlier findings and suggesting that catecholamine release in the adrenal is not necessarily coupled to an up-regulation of TH. The main finding of the present study is that prenatal exposure to nicotine impairs these responses in central catecholaminergic neurons and adrenals, which can possibly be related to the decreased ability to survive severe postnatal hypoxia. These results, obtained in the mouse, offer a basis for future respiratory studies in transgenic mice.

The catecholamine surge at birth has previously been demonstrated by measuring plasma levels of circulating catecholamines and the NA turnover in the brain $(9,14)$. In the present study we were able to analyze this surge at the transcript level, offering the advantage of early detection of cellular responses. Changes in mRNA levels offer an alternative way of studying neuronal responses and should be viewed as a complement to protein level measurement and physiologic studies. Although not a full-proof measure of biologic activity, since it may not be translated into protein, mRNA levels are useful to 

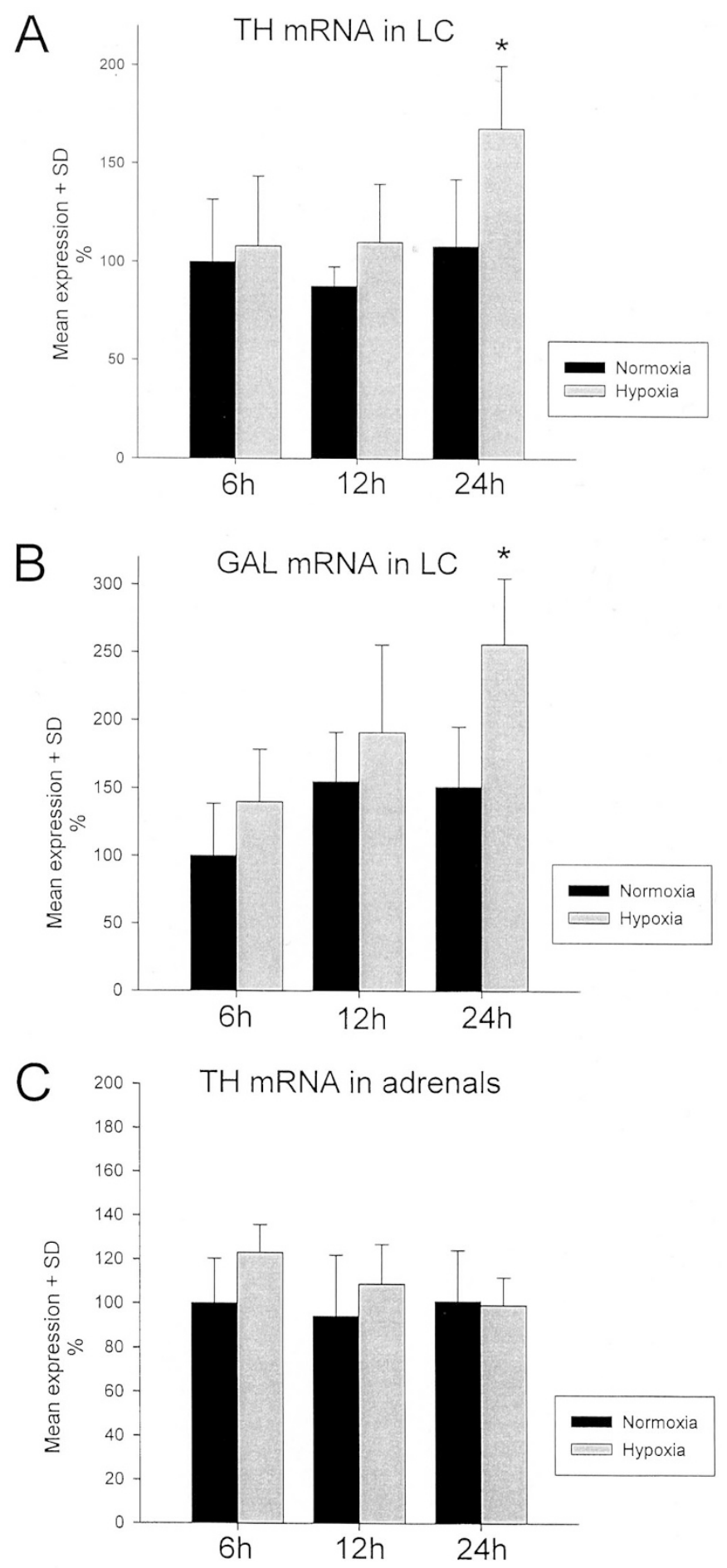

Figure 4. Expression of TH (top) and GAL (middle) mRNA in the LC, as well as of TH mRNA in the adrenals (bottom) at different times after postnatal hypoxia. Values are expressed as percentage of the normoxic group at $6 \mathrm{~h}$. Black bars represent control group, gray bars represent animals exposed to hypoxia. Significant increases of both TH and GAL mRNA were seen in the LC at $24 \mathrm{~h}$ after hypoxia $\left({ }^{*} p<0.05\right)$ compared with corresponding normoxic group. In the adrenals, no significant increases were found at any time after hypoxia.

study the response of the cell to a given stimulus. A relation between TH mRNA expression and enzyme activity has also been demonstrated recently (27). The present study was per-
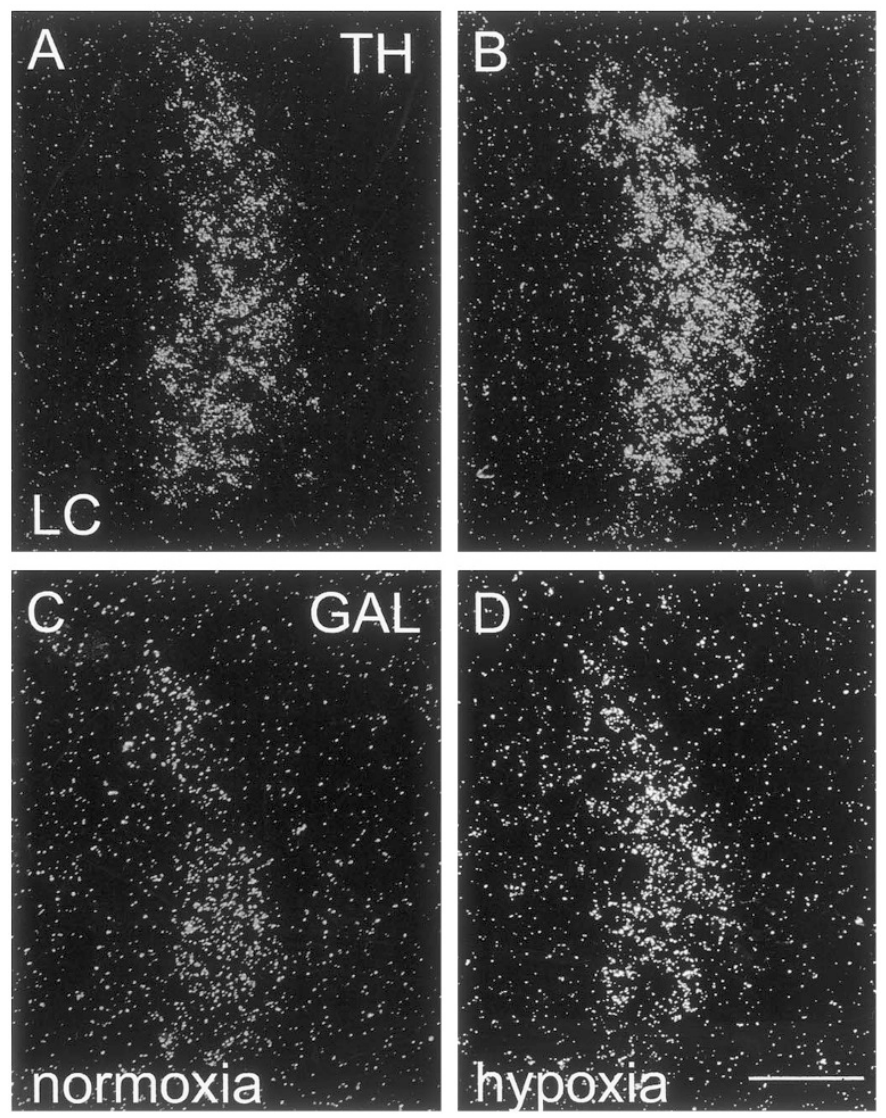

Figure 5. Darkfield images of the TH and GAL mRNA expression in the LC $24 \mathrm{~h}$ after a 60 min hypoxic period ( $B$ and $D$ ) compared with controls ( $A$ and $C)$. Both TH and GAL were up-regulated at this time. No significant increases were seen at 6 and $12 \mathrm{~h}$ after hypoxia (not shown). Images are transverse sections of the brainstem with the ventral surface facing downwards. Bar indicates $200 \mu \mathrm{m}$.

formed in the mouse, a species whose respiratory characteristics are similar to those of the rat, however, the mouse is considered relatively less mature at birth and also has a higher metabolic rate than the rat.

Postnatal expression of TH and GAL $m R N A$. Our finding that TH mRNA is up-regulated following birth in both LC and adrenals of the mouse is in agreement with previous findings in the rat adrenal $(15,28)$. Apart from the increased levels of circulating catecholamines following birth there is also an increased activity in the central catecholaminergic structures, as is indicated by the increase of NA turnover in the brain immediately after birth (14). In the adult rat, a catecholamine release following reserpine administration is coupled to a subsequent increase in TH mRNA, the rate-limiting enzyme of the catecholamine biosynthesis, in adrenals (29) and LC (30). The LC, also termed the A6 group, consists almost exclusively of noradrenergic neurons and projects to many areas of the brain $(31,32)$. This nucleus may thus be involved in the arousal of the newborn and the first breaths after birth (14). Also, its importance for respiration has been shown by unilateral cooling of the LC area, which altered the respiratory response to hypoxia (33), reversing the fall in respiratory rate that is typically seen in the immature animal (34). Although the direct effect of NA on respiratory neurons is inhibitory, it has been 

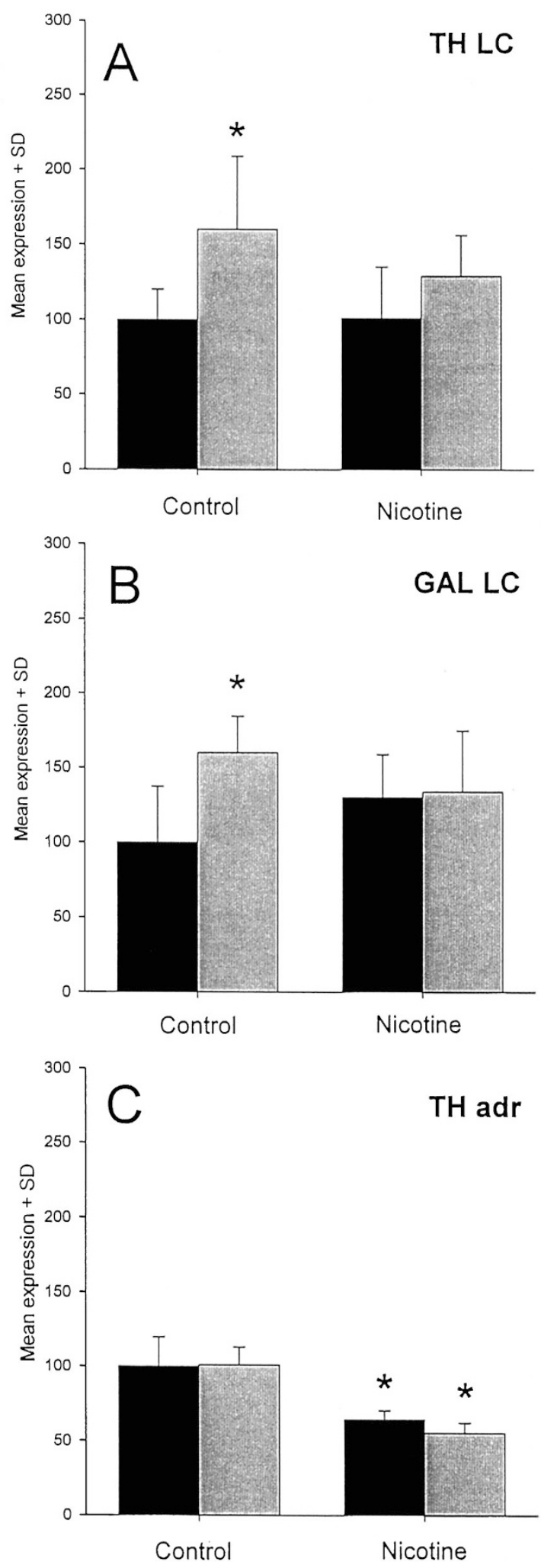

Figure 6. Expression of TH $(A)$ and GAL $(B)$ mRNA in the LC, as well as of TH mRNA in the adrenals $(C)$ at $24 \mathrm{~h}$ after postnatal hypoxia. Values are expressed as percentage of normoxic control group. Black bars represent control group, gray bars represent animals subjected to hypoxia. Expression of TH and GAL mRNA significantly increased after hypoxia in the control groups, but not in the nicotine group $\left({ }^{*} p<0.05, A\right.$ and $\left.B\right)$. In the adrenals, no response to hypoxia was seen either group. However, animals prenatally exposed to nicotine had significantly lower levels of TH mRNA expression $(* p$ $<0.05, C)$ proposed that the global effect is a stimulation of respiration $(35,36)$. Such a view is compatible with the presence of multiple CA cell groups and their differential projections in the rat brain $(31,37)$.

The activity of LC noradrenergic cells may also be influenced by the neuropeptide GAL as over $80 \%$ of the catecholaminergic neurons of the LC also have the capacity to synthesize and probably secrete GAL (8). Using in vitro extraand intracellular recordings, GAL has been shown to inhibit firing of LC neurons, and to cause hyperpolarization and a decrease in membrane resistance, probably via an increase in $\mathrm{K}^{+}$conductance $(38,20)$. Thus, GAL in the LC neurons is a potential modulator of the stress response seen in the newborn immediately after birth. We can here show that GAL mRNA expression increases postnatally in the mouse LC, as we have previously shown in the rat (21). In contrast to TH mRNA, GAL levels increase further after $24 \mathrm{~h}$. Similarities in expression patterns between TH and GAL mRNA have previously been seen in adult LC after reserpine administration $(30,39)$.

Effects of acute hypoxia on TH and GAL $m R N A$. Hypoxia, as well as anoxia, is known to increase levels of extracellular NA in the brain (16). In this study we show that such an increase of brain NA is paralleled by increased levels of TH mRNA in the LC $24 \mathrm{~h}$ after hypoxia on the first day of life. Furthermore, we show that GAL mRNA also increases in the LC $24 \mathrm{~h}$ after hypoxia, whereby the increase and expressional pattern resemble studies employing reserpine administration (30). The LC is also one of the proposed sites for central chemoreception of $\mathrm{CO}_{2}$ (for review see (40)), but this is an unlikely stimulus as the addition of $4 \% \mathrm{CO}_{2}$ does not induce hypercapnia during hypoxic hyperventilation (22).

The $\mathrm{O}_{2}$-sensing mechanism of the neonatal chromaffin cells in the adrenals leads to a release of catecholamines during hypoxia despite the absence of cholinergic innervation (12, 41). This catecholamine release is, however, not coupled to a subsequent increase in TH mRNA in the neonatal rat adrenal medulla (18). Our results are consistent with this view, showing no significant increases of TH mRNA. Hence, the ability to increase the expression of TH mRNA appears to be dependent upon neurogenic stimulation, which is further indicated by the fact that cholinergic receptor agonists acting on adrenomedullary cells leads to CA release with a subsequent TH mRNA increase (42). Another possibility that cannot be overlooked is that no further up-regulation of TH mRNA in the adrenals may be possible at that time, since levels are already high following birth. The fact that birth induces increased levels of TH mRNA, in contrast to postnatal hypoxia, indicates that the hypoxia associated with birth is not the sole factor responsible for this increase.

Effects of prenatal nicotine. The dramatic increase in mortality during the 60 min hypoxia period in the nicotine group compared with controls supports previous findings in rat (4). It has been hypothesized that the decreased ability to withstand hypoxia after prenatal exposure to nicotine is due to dysfunctions in the release of catecholamines, with a decreased release peripherally and a decreased turnover combined with an increased release of NA after hypoxia centrally (4). We therefore examined the expression of TH and GAL mRNA in the LC and 
adrenals after hypoxia in these animals. In the LC, basal levels of either marker do not differ significantly between groups. Such a difference, with decreased mRNA levels, could have reflected a decreased turnover rate in the nicotine group, as indicated by previous studies (4). It is however possible, as previously mentioned, that changes in the activity of the enzyme is not detected by measuring mRNA levels. Furthermore, TH mRNA after hypoxia is significantly increased in the control group but not in the nicotine group, possibly indicating a greater release of NA from LC neurons in the control group. Also, levels of GAL mRNA changed in a similar way. In the adrenals there were no differences in levels of TH mRNA after hypoxia in either group; this is in co-ordinance with the above-mentioned findings that hypoxia does not cause increases in TH mRNA expression in this organ. However, the levels of TH mRNA were significantly reduced in nicotine groups compared with controls $48 \mathrm{~h}$ after birth. To our knowledge, there are no previous reports on decreased levels of $\mathrm{TH}$ mRNA in the adrenals after prenatal exposure to nicotine.

We speculate that the difference in $\mathrm{TH}$ and GAL mRNA levels in the LC reflects an attenuated activity of the LC neurons and that this, together with a decreased level of catecholamine synthesis the adrenals, may affect the ability of the newborn to auto-resuscitate during severe hypoxia. Such an effect on autoresuscitation has indeed been seen in newborn rat during hypoxia (5). Furthermore, recent studies on ventilation in newborn rat have shown that animals exposed prenatally to nicotine have a disturbed ventilatory response to hypoxia (43). Thus a deficiency in respiratory control should also be considered as a possible primary cause of the increased mortality in nicotine treated animals.

Acknowledgments. The authors thank Siv Nilsson and Katarina Åman for their skillful technical assistance and to Viveka Karlsson and Karin Lagerman for secretarial assistance.

\section{REFERENCES}

1. DiFranza JR, Lew RA 1995 Effect of maternal cigarette smoking on pregnancy complications and sudden infant death syndrome. J Fam Pract 40:385-394

2. Lichtensteiger W, Ribary U, Schlumpf M, Odermatt B, Widmer HR 1988 Prenatal adverse effects of nicotine on the developing brain. Prog Brain Res 73:137-157

3. Slotkin TA 1992 What can we learn from animal models? In: Zagon IS, Slotkin TA (ed) Maternal Substance Abuse and the Developing Nervous System. Academic Press: San Diego, pp 97-124

4. Slotkin TA, Lappi SE, McCook EC, Lorber BA, Seidler FJ 1995 Loss of neonatal hypoxia tolerance after prenatal nicotine exposure: implications for sudden infant death syndrome. Brain Res Bull 38:69-75

5. Fewell JE, Smith FG 1998 Perinatal nicotine exposure impairs ability of newborn rats to autoresuscitate from apnea during hypoxia. J Appl Physiol 85:2066-2074

6. Tatemoto K, Rökaeus A, Jörnvall H, McDonald TJ, Mutt V 1983 Galanin - a novel biologically active peptide from porcine intestine. FEBS Lett 164:124-128

7. Melander T, Hökfelt T, Rökaeus A, Cuello AC, Oertel WH, Verhofstad A, Goldstein M 1986 Coexistence of galanin-like immunoreactivity with catecholamines, 5-hydroxytryptamine, GABA and neuropeptides in the rat CNS. J Neurosci 6:3640-3654

8. Holets VR, Hökfelt T, Rökaeus A, Terenius L, Goldstein M 1988 Locus ceruleus neurons in the rat containing neuropeptide $\mathrm{Y}$, tyrosine hydroxylase or galanin and their efferent projections to the spinal cord, cerebral cortex and hypothalamus. Neuroscience 24:893-906

9. Lagercrantz H, Bistoletti P 1977 Catecholamine release in the newborn infant at birth. Pediatr Res 11:889-893

10. Jones CT 1980 Circulating catecholamines in the fetus, their origin, actions and significance. In: Parvez H, Parvez, S. (ed) Biogenic Amines in Development. Elsevier/North Holland Biomedical Press: Amsterdam, pp 63-68
11. Padbury J, Agata Y, Ludlow J, Ikegami M, Baylen B, Humme J 1987 Effect of fetal adrenalectomy on catecholamine release and physiologic adaptation at birth in sheep. J Clin Invest 80:1096-1103

12. Seidler FJ, Slotkin TA 1985 Adrenomedullary function in the neonatal rat: responses to acute hypoxia. J Physiol (Lond) 358:1-16

13. Lagercrantz H, Slotkin TA 1986 The "stress" of being born. Sci Am 254:100-107

14. Lagercrantz H, Pequignot J, Pequignot JM, Peyrin L 1992 The first breaths of air stimulate noradrenaline turnover in the brain of the newborn rat. Acta Physiol Scand $144: 433-438$

15. Holgert H, Schalling M, Hertzberg T, Lagercrantz H, Hökfelt T 1991 Changes in levels of mRNA coding for catecholamine synthesizing enzymes and neuropeptide $\mathrm{Y}$ in the adrenal medulla of the newborn rat. J Dev Physiol 16:19-26

16. Seidler FJ, Slotkin TA 1990 Effects of acute hypoxia on neonatal rat brain: regionally selective, long-term alterations in catecholamine levels and turnover. Brain Res Bull 24:157-161

17. Nakajima W, Ishida A, Takada G 1996 Effect of anoxia on striatal monoamine metabolism in immature rat brain compared with that of hypoxia: an in vivo microdialysis study. Brain Res 740:316-322

18. DeCristofaro JD, LaGamma EF 1994 Neonatal stress: effects of hypoglycemia and hypoxia on adrenal tyrosine hydroxylase gene expression. Pediatr Res 36:719-723

19. Tsuda K, Tsuda S, Nishio I, Masuyama Y, Goldstein M 1992 Modulation of norepinephrine release by galanin in rat medulla oblongata. Hypertension 20:361-366

20. Pieribone VA, Xu ZQ, Zhang X, Grillner S, Bartfai T, Hökfelt T 1995 Galanin induces a hyperpolarization of norepinephrine-containing locus ceruleus neurons in the brainstem slice. Neuroscience 64:861-874

21. Wickström R, Holgert H, Lagercrantz H, Hökfelt T 2000 Perinatal distribution of galanin and galanin receptor-1 mRNA in the rat hindbrain. Dev Brain Res 123:53-65

22. Pepelko WE, Dixon GA 1975 Arterial blood gases in conscious rats exposed to hypoxia, hypercapnia, or both. J Appl Physiol 38:581-587

23. Murrin LC, Ferrer JR, Zeng WY, Haley NJ 1987 Nicotine administration to rats: methodological considerations. Life Sci 40:1699-1708

24. Vrontakis ME, Peden LM, Duckworth ML, Friesen HG 1987 Isolation and characterization of a complementary DNA (galanin) clone from estrogen-induced pituitary tumor messenger RNA. J Biol Chem 262:16755-16758

25. Grima B, Lamouroux A, Boni C, Julien JF, Javoy-Agid F, Mallet J 1987 A single human gene encoding multiple tyrosine hydroxylases with different predicted functional characteristics. Nature 326:707-711

26. Dagerlind A, Friberg K, Bean AJ, Hökfelt T 1992 Sensitive mRNA detection using unfixed tissue: combined radioactive and non-radioactive in situ hybridization histochemistry. Histochemistry 98:39-49

27. Shimizu H, Kumai T, Kobayashi S 2001 Involvement of tyrosine hydroxylase upregulation in cyclosporine-induced hypertension. Jpn J Pharmacol 85:306-312

28. Holgert H, Pequignot JM, Lagercrantz H, Hökfelt T 1995 Birth-related up-regulation of mRNA encoding tyrosine hydroxylase, dopamine beta-hydroxylase, neuropeptide tyrosine, and prepro-enkephalin in rat adrenal medulla is dependent on postnatal oxygenation. Pediatr Res 37:701-706

29. Vyas S, Faucon Biguet N, Mallet J 1990 Transcriptional and post-transcriptional regulation of tyrosine hydroxylase gene by protein kinase C. Embo J 9:3707-3712

30. Austin MC, Cottingham SL, Paul SM, Crawley JN 1990 Tyrosine hydroxylase and galanin mRNA levels in locus ceruleus neurons are increased following reserpine administration. Synapse 6:351-357

31. Dahlstrom A, Fuxe K 1964 Localization of monoamines in the lower brain stem. Experientia 20:398-399

32. Ungerstedt U 1971 Stereotaxic mapping of the monoamine pathways in the rat brain Acta Physiol Scand Suppl 367:1-48

33. Moore PJ, Ackland GL, Hanson MA 1996 Unilateral cooling in the region of locus ceruleus blocks the fall in respiratory output during hypoxia in anaesthetized neonatal sheep. Exp Physiol 81:983-994

34. Blanco CE, Hanson MA, Johnson P, Rigatto H 1984 Breathing pattern of kittens during hypoxia. J Appl Physiol 56:12-17

35. Errchidi S, Monteau R, Hilaire G 1991 Noradrenergic modulation of the medullary respiratory rhythm generator in the newborn rat: an in vitro study. J Physiol (Lond) 443:477-498

36. Bianchi AL, Denavit-Saubie M, Champagnat J 1995 Central control of breathing in mammals: neuronal circuitry, membrane properties, and neurotransmitters. Physiol Rev 75:1-45

37. Hökfelt T, Johansson O, Goldstein M 1984 Central catecholamine neurons as revealed by immunohistochemistry with special reference to adrenaline neurons. In: Björklund, Hökfelt (ed) Handbook of Chemical Neuroanatomy. Elsevier, Amsterdam, pp $157-276$

38. Seutin V, Verbanck P, Massotte L, Dresse A 1989 Galanin decreases the activity of locus ceruleus neurons in vitro. Eur J Pharmacol 164:373-376

39. Kadowaki K, Emson PC 1992 Increase in galanin gene expression in locus ceruleus neurones of the rat following reserpine treatment. Mol Brain Res 15:156-160

40. Nattie E $1999 \mathrm{CO}_{2}$, brainstem chemoreceptors and breathing. Prog Neurobiol 59:299-331

41. Thompson RJ, Jackson A, Nurse CA 1997 Developmental loss of hypoxic chemosensitivity in rat adrenomedullary chromaffin cells. J Physiol (Lond) 498:503-510

42. Slotkin TA, Seidler FJ 1988 Adrenomedullary catecholamine release in the fetus and newborn: secretory mechanisms and their role in stress and survival. J Dev Physiol $10: 1-16$

43. St.-John WM, Leiter JC 1999 Maternal nicotine depresses eupneic ventilation of neonatal rats. Neurosci Lett 267:206-208 